\title{
Analysis of heat losses of underground tunnel for engineering utilities with available methods
}

\author{
Oleg Brukhanov ${ }^{1}$, Andrey Rymarov ${ }^{1, *}$, Anna Malysheva ${ }^{1}$, Dmitriy Titkov ${ }^{1}$ \\ ${ }^{1}$ Moscow State University of Civil Engineering, 26, Yaroslavskoe Shosse, Moscow, 129337, Russia
}

\begin{abstract}
Methods for calculation of thermal regime and heat loss parameter for underground tunnel into surrounding sub-soil were developed in first half of XX century, when the study of complex heatmass exchange processes between underground tunnel, sub-soil and outdoor air is started. In tunnel it need to be provided a specific microclimate parameters, that requires a certain load on environmental control system. At present time there are some methods for calculation of heat loss parameter for underground tunnel. In this paper the analysis of real methods of calculation of heat losses of underground tunnel is accomplished.
\end{abstract}

\section{Introduction}

At present time the development of engineering communications, the industrialization and urbanization fatally lead to deficit of placement area for engineering utilities in big cities [1].

Underground placement of the communications in special tunnel providing the possibility of maintenance by stuff is good idea.

Network of underground communication tunnel extremely grows and is developed, that requires more detail its investigation in terms of providing with normative microclimate conditions influenced on durability and technical characteristics of communication utilities [2].

One of the key factors affected on tunnel microclimate is heat loss parameter. As underground tunnel is underground building with varied placement depth. Also heat emissions with different intensity take place. So heat losses are unsteady.

\section{Method of Kazantcev B.A.}

\subsection{Features of method}

Feature of the method is introduction of instability of heat loss parameter of underground realized due to using of the term «heat loss period» (hours). However the method is limited by depth of tunnel placement up to 10 meters [3].

\footnotetext{
*Corresponding author: rymarov@list.ru
} 
To apply the method of Kazantcev B.A. the method for calculation of sub-soil temperature around the tunnel depending of required depth of tunnel placement taking into account such parameters as heat loss period, sub-soil heat diffusivity, range of temperature variation [4] at sub-soil surface is necessary. It is realized by the method of Vlasov O.E.

For determination of calculated value of surface area for envelop building in tunnels with rectangular cross-section it is need to take into account the influence of corners in tunnel, increasing its heat loss values. It is achieved by addition to each inner geometrical size of tunnel of some parameter that takes account following parameters: heat loss period, heat conductivity and heat capacity as well as density of material for envelop building based in tunnel.

Heat-transfer coefficient is determined with the equation (1).

$$
k=\frac{1}{\frac{1}{\alpha_{\mathrm{B}}}+\frac{2 \cdot H+\sqrt{z \cdot \frac{\lambda}{\rho \cdot c}}}{3 \cdot \lambda_{\mathrm{S}}}},\left[W /\left(m^{2} \cdot{ }^{\circ} \mathrm{C}\right)\right]
$$

where: $\mathrm{H}$ is distance between ground-level and top of bridging, $\mathrm{m} ; \lambda$ is heat conductivity coefficient of envelop structure of tunnel, $\mathrm{W} /\left(\mathrm{m}^{2} \cdot{ }^{\circ} \mathrm{C}\right) ; \lambda_{s}$ is heat conductivity coefficient of sub-soil, $\mathrm{W} /\left(\mathrm{m}^{2} \cdot{ }^{\circ} \mathrm{C}\right) ; \rho$ is density of material for envelop structure in tunnel, $\mathrm{kg} / \mathrm{m}^{3} ; c$ is heat capacity of tunnel envelop structure, $\mathrm{kJ} /\left(\mathrm{kg} \cdot{ }^{\circ} \mathrm{C}\right)$.

\subsection{Calculations}

On the basis of this method for underground tunnel with rectangular cross-section $-4.83 \mathrm{~m}^{2}$, placement depth up to $10 \mathrm{~m}$ and embedment width $-1 \mathrm{~m}$, heat conductivity coefficient for clay loam sub-soil around the tunnel -1.18 and $1.26 \mathrm{~W} /\left(\mathrm{m}^{2} \cdot{ }^{\circ} \mathrm{C}\right)$ for dry sub-soil and frozen sub-soil, respectively as well as with constant air temperature in tunnel $-30{ }^{\circ} \mathrm{C}$ the calculations of heat loss parameters for Moscow city are accomplished. The results obtained are shown in Fig. 1 and 2.

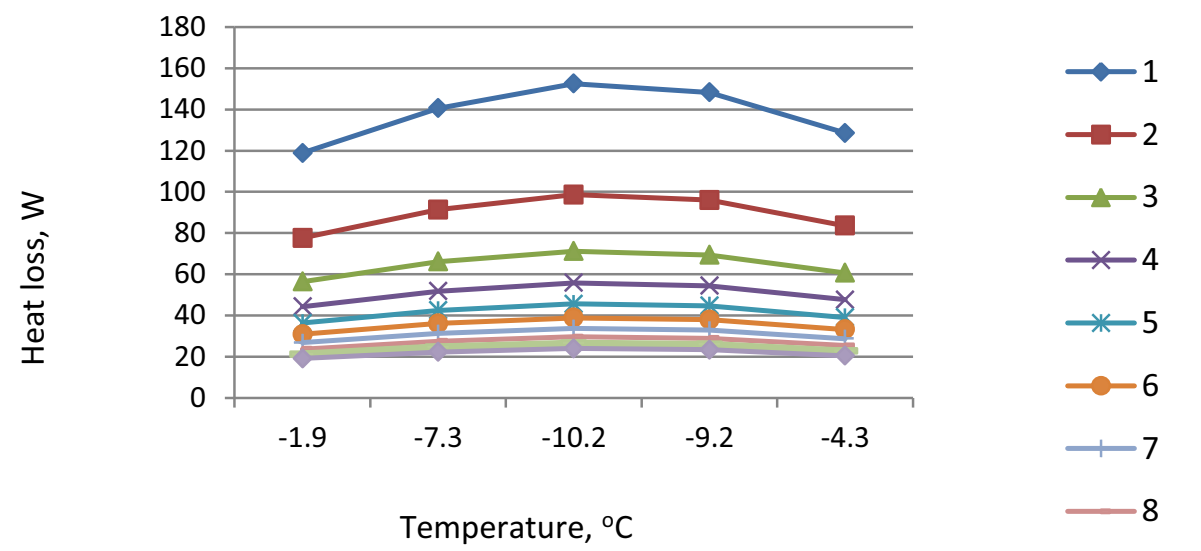

Fig. 1. Variation of heat loss parameter for underground tunnel into sub-soil during cold period depending on outdoor air temperature

Fig. 1 and 2 demonstrate the heat loss values are reduced with increasing of tunnel placement depth as well as season variation of outdoor air temperature. However, calculation method according to Kazantcev B.A. doesn't take account shape and size of building as well as thermal characteristics of surround sub-soil and indoor space heating time period. But it is necessary especially when presence of heating system in tunnel. This method is suitable only for tunnels placed at depth up to $10 \mathrm{~m}$. Also humidity of envelop 
structures is varied with time and effects on tunnel heat loss parameter. It is difficult to register with this method.

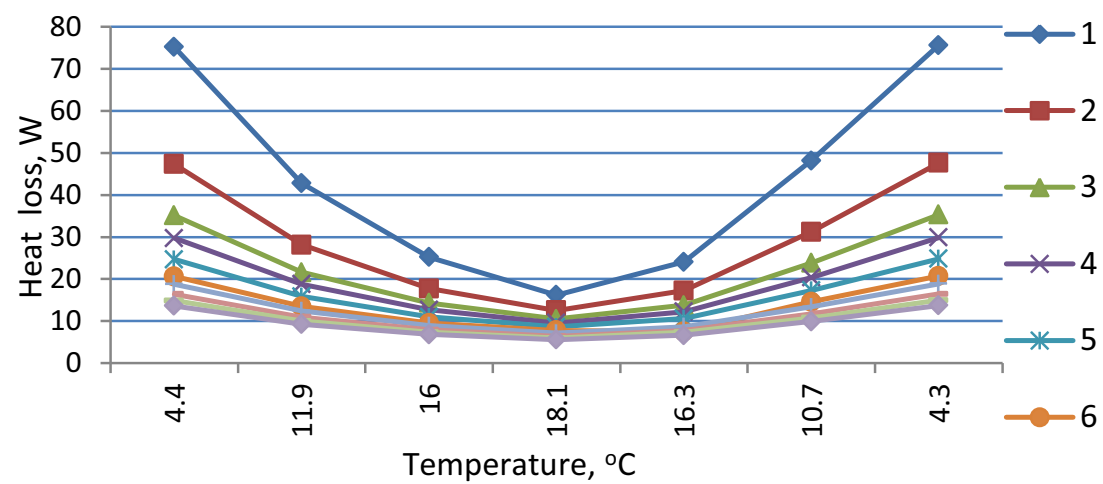

Fig. 2. Variation of heat loss parameter for underground tunnel into sub-soil during warm period depending on outdoor air temperature.

Introduction of air movement in tunnel with varied inner air temperature and heat loss parameter in the above methods was not accomplished $[5,6,7]$.

\section{Method of Machinsky V.D.}

Calculation of heat loss parameter for communication tunnel into surround sub-soil by prof. Machinsky V.D. method is considered. In this case a heat loss parameter is calculated for floor slab, wall and floor separately [3,8].

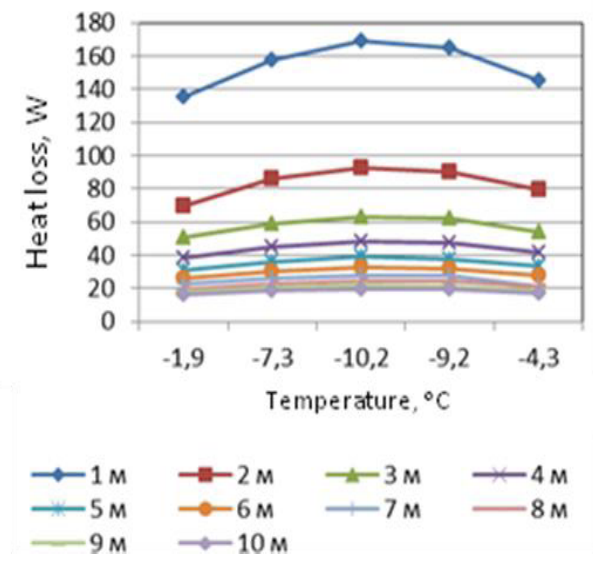

Fig. 3 Variation of heat loss parameter for underground communication tunnel into sub-soil during cold period depending on outdoor air temperature as well as a replacement depth of tunnel.

As an example the dimensions of underground tunnel with fixed cross-section $-4.83 \mathrm{~m}^{2}$ are used. The tunnel placement depth in range of 1-10 $\mathrm{m}$ with 1-meter interval and fixed inner air temperature $-+30{ }^{\circ} \mathrm{C}$ was studied assuming the presence of heating system in tunnel for town or region.

The calculation of heat loss parameter during a year for Moscow climate taking [9] into account the monthly average air temperature according to SP 131.13330.2012 «Construction climatology» is accomplished. As sub-soil a clay loam with heat conductivity coefficient 1.18 and $1.26 \mathrm{~W} /\left(\mathrm{m}^{2} \cdot{ }^{\circ} \mathrm{C}\right)$ for dry sub-soil and frozen sub-soil, 
respectively was used. On the base of results of calculation the diagrams of effect of monthly average air temperature in cold period on heat loss parameter of underground tunnel taking into account different tunnel placement depth are obtained (Fig. 3, 4).

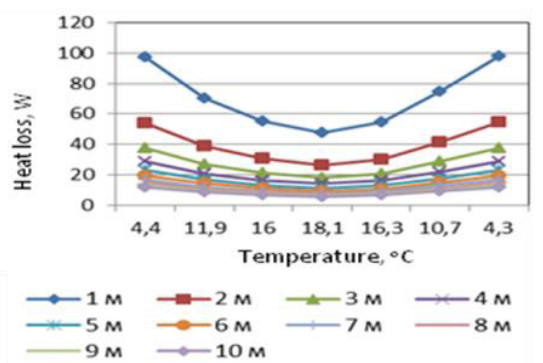

Fig. 4 Variation of heat loss parameter for underground communication tunnel into sub-soil during warm period depending on outdoor air temperature as well as placement depth of tunnel.

Choice of design temperature for heat loss through sub-soil layer depends on sub-soil mass with varied width and thermal properties that is not taken account in this method.

\subsection{Analysis of V.D. Machinsky method and method developed in Teploelectroproect Institute}

The method developed in Teploelectroproect Institute takes into account climate condition of construction region, ambient sub-soil temperature on depth of tunnel placement as well as shape of tunnel cross-section but depth of tunnel placement relatively the ground level as well as sub-soil heat conductivity coefficient. The V.D. Machinsky method takes into account tunnel shape and sub-soil characteristics depending on tunnel placement depth but climate conditions.

As an example the underground tunnel with cross-section $-4.83 \mathrm{~m}^{2}$ and fixed inner temperature $-+30{ }^{\circ} \mathrm{C}[10]$ is used. The calculation of heat loss parameter during a year for Moscow city on the base of monthly average air temperature for each month of a year are curried out. As sub-soil a clay loam with normative depth of soil freezing $-1.3 \mathrm{~m}$ for Moscow city was used.

The calculation of heat loss parameter other factors being equal are realized and shown in Fig 5.

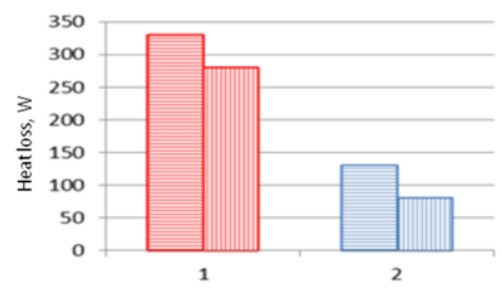

Fig. 5. Heat loss into sub-soil mass in cold period (1) warm period (2), horizontal hatching according to method of Teploelectroproect Institute, vertical hatching - by V.D. Machinsky method.

Differences between the calculation results for the both methods are within $15 \%$

\section{Summary}

Heat balance is dominant factor when required microclimate formation in underground tunnel [11]. Available methods for calculation of unsteady heat losses by underground buildings take into account such factors as depth of underground building placement, and 
shape as well as sub-soil properties etc. $[12,13,14]$ with different limitations. One of the problem of the methods is inability of determination of time period shift of maximal/minimal temperature variations and heat losses by underground tunnel relatively outdoor air temperature varied with time including the building dimensions $[15,16]$. It makes difficult of control of equipment operation. In the above methods the air movement in tunnel effecting on inner air temperature and heat losses is not taken into account.

\section{References}

1. O. Samarin, K. Lushin, S. Paulauskaite, Technological and Economic Development of Economy 13, 67-72 (2007)

2. O. N. Brukhanov, D. G. Titkov, Internet-Bulletin VolgGASU 33, 16 (2014)

3. V. Gagarin, V. Kozlov, K. Lushin, International Journal of Applied Engineering Research 23, 43438-43441 (2015)

4. A. G. Rymarov, D. G. Titkov, Construction: science and education 4, 2 (2014)

5. S. A. Isaev, N. I. Vatin, S. V. Guvernyuk, V. G. Gagarin, B. I. Basok, Y. V. Zhukova, High Temperature 53, 873-876 (2015)

6. V. N. Varapaev, A. V. Doroshenko, Procedia Engineering 91, 200-203 (2014)

7. A. Volkov, A. Sedov, P. Chelyshkov, E. Kulikova, Applied Mechanics and Materials 584-586, 761-764 (2014)

8. V. Bodrov, M. Bodrov, K. Lushin International Journal of Applied Engineering Research 22, 43277-43280 (2015)

9. A. G. Rymarov, Natural and technical sciences 63, 380-382 (2013)

10. A. G. Rymarov, Academia. Architecture and building 5, 362-364 (2009)

11. A. G. Rymarov, Natural and technical sciences 62, 595-599 (2012)

12. A. G. Rymarov, K. I. Lushin, Science, construction, education, (2011) Information on http://www.nso-journal.ru.

13. N. Parfentieva, O. Samarin, K. Lushin, S. Paulauskaite, ICEE 2008 - Conference Proceedings, 854-858 (2008)

14. V. Gagarin, A. Y. Neklyudov, International Journal for Housing Science and Its Applications 39, 79-87 (2015)

15. Y. Kharkin, E. Korol, A. Davidyuk, Procedia Engineering 117, 172-178 (2015)

16. A. G. Rymarov, K. I. Lushin, Science, construction, education, (2012) Information on http://www.nso-journal.ru.

17. A. G. Rymarov, D. G. Titkov, Natural and technical sciences 80, 144-147 (2015) 